\title{
Position Paper: Creating a New Professional Association
}

\author{
By David Arendale, Hilda Barrow, Kathy Carpenter, Russ Hodges, Jane McGrath, Pat Newell, and Jan Norton
}

\section{Continual focus on improving member services is a hallmark of CRLA and NADE.}

\begin{abstract}
David Arendale
University of Minnesota-Twin Cities

arendale@umn.edu
\end{abstract}

Hilda Barrow

Pitt Community College

hbarrow@email.pittcc.edu

Kathy Carpenter

University of Nebraska at Kearney Emerita carpenterk@kearney.net

Russ Hodges

Texas State University-San Marcos

rh12@txstate.edu

Jane McGrath

Paradise Valley Community College, Emerita

janemcgrath@cox.net

Pat Newell

Edison State College

pnewell@edison.edu

Jan Norton

University of Wisconsin-Oshkosh

nortonj@uwosh.edu
ABSTRACT: This position paper investigates the merits and potential benefits of creating a new, more comprehensive professional association for members of the learning assistance and developmental education profession. This task was assigned to the College Reading and Learning Association/National Association for Developmental Education (CRLA/NADE) Working Group by the CRLA and NADE national executive boards. This Working Group considered not only the issue of effectiveness of the current professional associations but also the merits of expanding the mission and vision of a new professional association. Building upon the success of CRLA and NADE, the Working Group identified many ways a new association could better serve members and have a greater influence on student success and in society (CRLA/NADE Taskforce, 2007).

Continual focus on improving member services is a hallmark of CRLA and NADE. These two associations, along with three others in 2004, conducted a joint strategic review of their organizations and the fields they serve. National leaders were selected by their respective associations to serve on a Blue Ribbon Commission (BRC, 2006) and create a report based on their findings. The final section of the report focused on potential actions to improve service to their members and deal with the evolving postsecondary education environment.

Rather than recommending a single future path, the BRC report identified a multifaceted path including three aspects: coordination, collaboration, and creation. The first path would lead CRLA, NADE, and other organizations to better coordinate their activities in order to avoid duplication of services. The second course, collaboration, sought to find projects of mutual interest and savings that the current organizations could jointly offer to their members. The third path was creating a new professional association with expanded vision, mission, and resources to serve a wider group of professionals within postsecondary education.

As the BRC Report was disseminated within the postsecondary education community, discussion and excitement was generated about the possibility of creating a new professional association. In Spring 2007, the national executive boards of CRLA and NADE selected a group of past and current national leaders to serve as a work group charged with investigating the creation of a new professional association (CRLA/ NADE Taskforce, 2007).

We believe that the most compelling reasons for change within our profession are to increase the quality and quantity of professional development offerings for members, to broaden our impact in the profession, and to increase influence within society.

CRLA and NADE host excellent chapter and national conferences. However, a careful review of other postsecondary professional associations reveals they offer a wider spectrum of services for their members through knowledge-laden websites, multiple publications, on-line conferences, webinars, and research that identifies best practices for their members.

Based on a variety of national studies of developmental education, Boylan (1995) estimates more than 107,000 personnel work in the field served by CRLA and NADE. However, only approximately $5 \%$ of them are members of these two associations. A new association would be more attractive to nonmembers if they could access a wider variety of services along with conferences. This Working Group also identifies that there are groups outside the current profile of CRLA and NADE association members within postsecondary education that could find affiliation with a new organization desirable. A new association with an expanded mission, vision, and more inclusive language could encourage active membership by these groups.

We completed the first draft of the full report in June 2007 (http://www.crla.net/WorkingGroupReporto91007.doc). Although we concluded unanimously that a new professional association would be beneficial, we also concluded that the change process would be difficult and significant. We recognize that the easiest course is to make incremental changes within the current structures. However, we believe that dramatic reinvention and transformation is needed to meet the quickly changing needs of the profession and the environment in which it oper- 
ates. A term used to describe such change is "leapfrogging" (Harbison \& Pekar, 1998; Nonaka \& Nishiguchi, 2001). Instead of "fixing" an old process, it is "leapfrogged," and a new process is introduced. The often-cited classic example is how emerging countries are designating cell phones as the primary communication channel and skipping the wiring of the countryside with traditional telephone wires. The cost of the new technology and ease of implementation is much less than following all steps through the older technology. The Working Group strongly supports leapfrogging with the creation of a new professional association rather than attempting to retool the older ones. The synergy of a larger organization with more assets and a fresh start presents many opportunities. The best practices of other national associations can be integrated into this new design.

However, it is critical to remember that creating a new organization does not mean that the history and traditions of the previous ones will be discarded and ignored. The best and most cherished traditions from each would be retained while carefully crafting and implementing new ones to complement and enhance them. The most important preservation of the past organizations lies within the members of these groups: CRLA and NADE are not defined only by their previous conferences, publications, and awards, but by their members. If careful groundwork is laid to create an inclusive and even more beneficial professional association, this cohort of previous members will walk into the future and be joined by new colleagues.

This position paper and the full online report is another step in a wider conversation about the future. More voices, perspectives, and ideas are needed to build consensus regarding leadership actions. We have the opportunity to carefully and deliberately manage change in these turbulent times. This is a great opportunity for our profession to take bold, new steps to meet the needs of our members, our profession, and our society.

\section{Analyzing the Question of Change for the Profession}

The authors were guided by several overarching questions as they investigated creation of a new professional association: What form of organization is needed to perform needed functions that are essential for meeting the new mission? Is a new professional association good for the association members? Based on the discussion that ensued from examining those two questions, additional ones were generated. These served as the major report sections of the complete online report as well as this summary position paper.

\section{Why Create a New Professional Association?}

Major change within any organization should be carefully considered. Creation of a new professional association should be done only if there are clear and compelling arguments in its favor. The first question that the CRLA/NADE Working Group sought to answer was "What are the advantages of no change, and what are the threats to the current associations and their members without a transformation?"

Sample advantages of "no change" include: (a) the change process-sometimes difficult due to inertia and fear of the unknown-is not engaged, (b) risk of the unknown is avoided, (c) name recognition of current organizations is maintained, (d) the familiar is not abandoned and historic traditions remain unchanged, (e) individual cultures would be preserved (smaller organizations perceive that their culture would be suppressed and replaced by the culture of the larger one), and (f) financial uncertainty and

\section{Dramatic reinvention and transformation is needed to meet the quickly changing needs of the profession and the environment in which it operates.}

risk posed by a new organization is lessened.

The opposite position was also investigated. What are the threats and dangers of not making change now? Sample disadvantages of "no change" include: (a) competition between several major national professional associations in this field serving essentially the same population would continue, (b) no central voice would represent the field and the students who are served, (c) prestige associated with being a member of current professional associations is minimized due to stigma issues attached to the field by external stakeholders, (d) sufficient research and scholarship is unavailable from current organizations to meet needs of their members, (e) assets among the multiple organizations (e.g., leaders, members, financial assets, other resources) remain divided, (f) professional development opportunities (e.g., conferences) and certification programs are duplicated, (g) status quo leads to complacency and lack of innovation, (h) diminished financial support at host institutions of an increasing number of current members will curtail state and national conference attendance, and (i) national associations would not be aligned with various chapters that are already combining state or regional conferences. They are already moving towards creation of a single organization representing professionals at the state or regional level.

After completing this careful analysis, the CRLA/NADE Working Group believed that the threats to the health and future of both organizations of no change were overwhelming compared to the reasons supporting no change. It is for this reason that the authors strongly advocate for continuing the conversation for proactive change and transformation in creating a new more inclusive national association.

\section{Who Are the Potential Members and What Benefits Do They Need?}

Our group identified categories of professionals that are potential members of the new professional association. For some groups, providing member services online will be especially critical. Reliance upon the national and even state/ regional conference as the primary provider of service will become increasingly insufficient and ineffective for busy professionals with multiple job responsibilities, adjunct/part-time status, and limited or eliminated travel funds. The national budget crisis confronting postsecondary education is unlikely to ease anytime soon, despite the injection of stimulus money by the federal government. Travel to conferences at the state and national level will be constrained or eliminated in many states. Online services are key to serving and retaining members. Other major national professional associations are already doing this.

Primary members retained from the existing organizations. Many of these categories of professionals are already members of CRLA and NADE such as (a) instructors of developmental courses (English, reading, mathematics); (b) instructors of learning strategies courses; and (c) professionals in peer learning assistance programs, academic support programs, and learning assistance centers. Approximately 50,000 faculty members teach developmental-level courses (Orlans, 1996). However, a small minority of them have full-time teaching assignments for this area. Nearly three-quarters of these instructors are either adjunct, part-time, or fulltime faculty assigned to teach developmental courses on a part-time basis (Boylan, Bonham, Jackson, \& Saxon, 2000). A cursory review of membership data for the learning assistance and developmental education organizations as a whole or special interest groups for adjuncts suggests than many faculty members of developmental education courses are not members of the current associations. Perhaps this is primarily due to an inability to attend the current conferences, lack of personal funds for membership, 
or lack of perceived value from current benefits of membership.

New membership groups for the association. Some professionals from these new groups are represented in CRLA and NADE. However, there are many more from these categories who are not currently affiliated with either organization. A sample of these underrepresented groups includes (a) peer mentoring and coaching (academic or personal); (b) graduate students interested in careers related to this field; (c) First-Year Experience courses and programs; (d) TRIO administrators, staff, and faculty members; (e) distance learning administrators concerned with providing academic support for on-line learners; (f) high school-to-college bridge programs; and (g) administrators at the dean level or higher who have interest in the field represented by this new association. The membership services and conference programming could be expanded to meet the needs of these new groups.

\section{What Services Could Be Provided to Members of the New Association?}

The most important reason for creation of a new professional association is for a dramatic increase of quantity and quality of professional development services for its members. These services are based upon our Working Group's best judgment of services needed by this diverse collection of members. A robust list of member services requires a comprehensive, coordinated, and flexible organization to meet current and future needs of the members and other stakeholders. Other leading national associations that are similar in size or larger than NADE and CRLA commonly provide these services.

Supportive home. Members must be able to find a comfortable and supportive "home" within the association. These communities may be of varying sizes and of different types. Members have choices concerning how many and what types to join. Members create their own web of support within the larger association based on their decisions. The groups are defined by different characteristics: job function, academic content areas, topic areas, demographics, and institutional characteristics. They provide niches for those with similar interests and backgrounds to meet, share, and obtain needed information for their jobs. They provide smaller "learning spaces" and "comfort zones" for the members within the larger group.

Additional scholarship. Building upon the current expertise of excellent national, regional, and state conferences and several journals currently published or supported by CRLA and NADE, the new association could offer a wider array of learning opportunities. More publica- tions are needed. Some would be included with basic membership; others would require additional fees. All publications would be marketed to other organizations and the general public. These could include practitioner-level journals, research journals, monographs, newsletters, books, reports, training manuals, curriculum guides, and other publications available through an enriched association website. In addition to print and online publications, people resources are essential. Knowledge communities where members can locate specific information related to their interest and job-related questions are key. More than traditional SIG and SPIN groups, these communities serve as a major generator and provider of information for members.

Expanded certifications. Recognition programs for members are critical. Building upon the current programs pioneered by CRLA and NADE, a new association could offer expanded professional certification opportunities for individuals or programs in learning centers, peer

\section{Compelling and useful services must be available on-line to complement the already excellent conferences.}

learning, developmental-level courses, mentoring, and tutoring that build upon the current programs. The certification could be for individual members, student paraprofessionals, and programs. Current and new award and scholarship programs would recognize excellence in the field and support professional development as well as scholarship.

Expanded technology infrastructure. A wide variety of venues from which to access information, research, and support from the association is essential. In addition to national and chapter conferences, new venues for professional development and support could be provided. These include regional training workshops, on-line workshops and webinars, and on-demand training through the association website.

In addition to traditional conferences, members could access information through more publications and their desktop computer. The technology would also provide association chapters the ability for members to more easily network and access information locally from throughout the U.S. and other regions of the globe. Revenue, training, and expertise would be shared with chapters to support work with members.
Compelling and useful services must be available on-line to complement the already excellent conferences. Heavily emphasized online resources can meet the needs of current CRLA and NADE members who are unable to consistently attend conferences. These services will appeal to others who share the vision and mission of the new association.

Advocate for the field. The new association would advocate on issues of importance to individual members, serve the public good, and define the field and educate stakeholders and policy makers. In addition, national standards of practice would be created and disseminated as well as ethical practices for the field-all done to advance the field and serve its members.

\section{What Are Useful Design Principles for Authority and Responsibility Delegation?}

There are common design principles that can successfully guide the proposed association. These are based on a careful review of more than a dozen national professional associations, some similar in size to CRLA and NADE and some larger organizations. These design principles require both financial and human capital. These are investments in a new approach for meeting the needs of current members and those who will join the new association.

Distribute authority and responsibility more widely. A larger, more complex professional association will require greater distribution of responsibility than currently exists with CRLA and NADE. Today, expansion of association services is limited by the reliance on a small number of volunteer leaders to both complete traditional executive board duties and administer the association on a day-to-day basis. In the new professional organization, the Executive Policy Board must have more time to focus on more traditional tasks such as budget formation, strategic planning, and major policy decisions and less on day-to-day management issues.

Expand board. We envision an increase in the size of the association-wide Executive Policy Board. Additional board-level officers are needed to provide leadership and mentorship for expanded services to members and represent the interests of affinity groups within the organization. With this, the new association would develop a variety of formal systems for providing advice and counsel to the national policy board along with other means for more participation by the rank-and-file members regarding advice and decision-making.

Expand paid professional staff. With higher levels of service provided to members, full-time

CONTINUED ON PAGE 32 
CONTINUED FROM PAGE 30

professional staff needs to be added to take on essential responsibilities such as administrative assistance, conference management, membership services, and other duties assigned by the association-wide Executive Policy Board.

Diversify income. Revenue sources will be developed in addition to the national conference and membership fees. This would include additional books, journals, and monographs published by the association as well as additional fee-based professional development opportunities (e.g., regional conferences on focused topics, on-line training workshops, webinars, and certifications).

\section{How Could a New Professional Association Be Organized?}

Adopting a new organizational form is essential to achieving the mission and functions of the new professional association. Specific and detailed organization charts are not provided in this position paper since they are premature and would draw attention from the overall design elements. It is premature to identify a firm organization pattern until the more essential issues of member benefits, organization functions, and design considerations are decided. However, based on successful practices by other postsecondary professional associations, we provide the following organization elements to serve as a starting point for a wider conversation.

General membership. The general membership should directly influence the decision-making process. This would require creativity to add venues to the traditional membership meeting at the annual national conference. With advances in emerging technology, Town Hall Meetings could be conducted online to offer an opportunity for wider participation. More use of annual surveys of membership on key issues would also involve them.

Executive staff. Building upon the current employment of part-time staff for membership, website maintenance, and conference management, a full-time position would be created to increase service to members. Contingent upon growth of membership, the staff would be expanded to a multiperson unit.

Advisory groups for the association-wide Executive Policy Board. The following advisory groups would provide formal counsel to the association-wide Executive Policy Board (EPB). Each would have specific responsibilities and reporting lines to the EPB.

1. Past Officers Council. This could include all past association-wide Executive Policy Board members of the previous associations.
2. Blue Ribbon Advisory Board. These nationally- and internationally-renowned experts and leaders in the field of postsecondary education would provide advice to the association on key strategic issues. Most members would be external to the association's field.

3. CLADEA Fellows. This group would provide advice similar to the Blue Ribbon Advisory Board and communicate in the same manner. Most members would be internal to the association's field.

4. Leadership Congress. This group would be composed of the association chapter presidents, association-wide committee chairpersons, and other leaders of the association. This group would meet preceding the national conference.

5. Town Hall Meetings. The voting membership of the association would be eligible to participate in Town Hall Meet-

\section{A portion of each individual's association dues would be shared with the chapter serving the geographic area in which the member works.}

ings. This group could meet in conjunction with the national conference and also through an on-line venue to present feedback and policy changes for consideration by the board. This could include use of technology for electronic voting.

Operating Divisions. These are the largest groups within the association. An operating division is defined as having its own knowledge base, theory, and research and producing its own scholarship. Individual members would select at least one division with which to affiliate when joining or renewing membership. Affiliation with more than one division would incur an additional annual membership fee. Divisions would be responsible for sponsoring one or more knowledge communities, publishing a newsletter, and generating other scholarship and professional development activities for members. Divisions would also have the opportunity to publish a journal that required an additional annual membership fee. To foster opportunity for innovation and experimentation, limited autonomy is granted to each operating division. Each division would conduct an election for a national representative (e.g., vice president). Depending upon the composition of the association-wide Executive Policy Board (discussed following), each of the vice presidents might serve on the policy board or report to a VP for Operating Divisions. Such Operating Divisions might include administrators, faculty, and staff involved in (a) developmental and college reading, (b) developmental and college English, (c) developmental and college mathematics, (d) learning assistance centers (tutoring/peer-assisted learning which could include Supplemental Instruction and Peer-Led Team Learning programs), (e) study and learning strategies courses and programs, (f) graduate programs serving teaching professionals for our field, and (g) postsecondary education. This general category group provides a home for members of the association who do not find a natural fit with one of the other categories. If sufficient members within an Operating Division with a similar new affinity join the association, consideration could be made to establish them as a new Operating Division.

Knowledge Communities. These are intermediate-sized groups within the association. They provide more in-depth information on focused topics. Functions provided by these communities would include a website with rich content materials, publications (e.g., newsletter, monographs, and training materials), mentors available to provide expertise to inquirers, and a listserv. This would be a significant extension and expansion of the current SIG and SPIN groups within CRLA and NADE. To assure high quality and provide mentorship for leaders, these appointed Knowledge Community leaders would report to a vice president on the association-wide Executive Policy Board. If a Knowledge Community grew to a sufficient size, it might be granted status as an Operating Division and join the list above.

Caucus Groups. A smaller unit within the association is a Caucus Group. This optional group is formed on the basis of institutional characteristics, personal demographics, or a small number of members focused around a job function or topic. If a group grows to a sufficient size, it might be granted status as a Knowledge Community. Caucus Groups can serve as an incubator for the creation of larger affinity units within the association. Such examples include (a) interest caucus (e.g., academic support for distance learning programs, enrollment management, English as a Second Language), (b) institutional characteristic (e.g., private liberal arts colleges, research universities), and (c) personal demographic (e.g., graduate students, international members, adjunct teachers--either part-time at

CONTINUED ON PAGE 34 
CONTINUED FROM PAGE 32

an institution or only teaching part of academic load with developmental-level courses).

Committees and task forces. The smallest units operating within the association with a narrow function defined by the By-Laws or Association Policy Manual would be individual committees and task forces. The association president would delegate responsibility for many of these groups. Some could be assigned to other Executive Board members.

Geographic regions. The organization would be divided into geographic regions. Chapters would operate within these regions. These chapters would either represent a single state, several contiguous states, a country (e.g., Canada), or a region of the world (e.g., Pacific Rim). A delegate selected by the chapters located within a region would have direct representation to the association-wide policy board through a Vice President of Regions.

The Vice President of Regions. This vice president would be responsible for administering services to chapter leaders and regional representatives and would ensure provision of training for these leaders via distance learning technologies. Chapter and regional leaders would meet during the annual conference to serve as an advisory group to the associationwide policy board, participate in the annual Leadership Congress, and participate in leadership and professional development activities.

Conferences. Conferences could occur at the state level or be held in conjunction with several state or regional chapters as they see fit. Membership in the association provides membership in a corresponding affiliated chapter. A portion of each individual's association dues would be shared with the chapter serving the geographic area in which the member works.

Many of the organizational elements identified in this section already operate within CRLA and NADE. A larger, more comprehensive organization needs a larger, more comprehensive system to ensure stability, proper management, leadership, member participation and voice, and a place of comfort and support for individual members. Following the principles of "form follows function" (Sullivan, 1896), the organization of a new association actually emerges from the wider discussion of mission, vision, services for members, and other related issues.

\section{Potential "Next Steps" for the Conversation}

Although the CRLA/NADE Working Group was diverse in its representation of past and present leaders in the field, this discussion needs more voices and perspectives to enrich the discussion, commit to change, and improve the design for the future. We recommend the following events to continue the conversation.

\section{Extend the Conversation to Wider Circles}

The Working Group's complete report has been circulated among the national executive boards for CRLA and NADE. It has also been placed online with announcement links sent to all CRLA and NADE members. Town Hall meetings have been held at the national conferences for CRLA and NADE. Surveys about the report were distributed to attendees at the recent NADE conference. However, it is important to include more stakeholder groups. More voices will enrich the conversation and generate a more powerful and purposeful proposal for consideration. Following is a sample of groups that could engage in this conversation simultaneously and provide synergy to the generation of ideas. Some of these groups include: (a) past national officers

\section{The best of past traditions can be brought into the future and merged with new structures and traditions, or all can be left to chance.}

and leaders of CRLA and NADE, (b) current and past national leaders of CRLA and NADE (e.g., committee, SPINs, SIGs), (c) chapter leaders of CRLA and NADE, (d) national education leaders, and (e) experts outside of learning assistance and developmental education (e.g., U.S. Department of Education, Lumina Foundation, other national education centers or foundations).

\section{Learn More About the Issues}

As the conversation continues, we also recommend conducting more research about other professional associations (e.g., organization, member services, use of full-time office staff, budget issues) and learning how other associations have worked together to create a new organization to better serve the needs of current and new members. Charge the existing CRLA/ NADE Working Group to serve as a coordinating committee for this investigative process by the two national executive boards. Additional appointees to the group by CRLA and NADE would add more voices and could include those with selected technical expertise (e.g., budget). The group would continue to report directly to the two national executive boards. A more de- tailed outline of next steps is contained in the full, online report.

\section{Conclusion}

A reoccurring question examined by the CRLA/ NADE Working Group has been "why change?" In the full report available online (http://www. crla.net/WorkingGroupReporto91007.doc) we carefully explored the pros and cons of creating a new association and provided numerous suggestions for its services and organization structures. A better question than "why change?" is "what kind of change is demanded by postsecondary education and needed by these professionals?" Perhaps an analogy provided by Shakespeare can provide a paradigm for us when considering the future. When writing a dialogue among several of his characters in a play discussing the future, Shakespeare penned the expression "The Undiscovered Country" to describe this place. Although everyone will visit the future, no one can come back and tell others exactly what it will be like. However, all of us will walk into The Undiscovered Country.

The members of CRLA and NADE have a choice regarding how they will walk into the future. Change can be simply reacted to or proactively managed. The best of past traditions can be brought into the future and merged with new structures and traditions, or all can be left to chance. The most important element that moves forward into the new association is the members of the current organizations. They form the core of the new future and bring forward the history and traditions of the previous organizations. Let us encourage new members to join these veterans and walk together into The Undiscovered Country as colleagues and friends. Let's create a dynamic new association together.

\section{Sharing Your Comments}

The national executive boards of CRLA and NADE welcome comments by readers of this article. Please direct comments to NADE Secretary BettyBlack,kfbjboo@tamuk.edu and/or CRLA Newsletter Editor Linda Russell, linda.russell@ minneapolis.edu.

\section{References}

Blue Ribbon Commission (BRC). (2006). Creating a new vision for the future: A report from the Blue Ribbon Commission. Retrieved June 24, 2009, from the University of Minnesota-Twin Cities Website: http://www.tc.umn. edu/ arendo11/BRCSWOTReporto20106.pdf

Boylan, H. R. (1995). The scope of developmental education: Some basic information on the field. Research in Developmental Education, 12(4), 1-4. 
Boylan, H. R., Bonham, B. S., Jackson, J., \& Saxon, D. P. (1994). Staffing patterns in developmental education programs: Full-time positions, credentials, and program placement. Research in Developmental Education, 11(5), 1-4.

CRLA (College Reading and Learning Association)/NADE (National Association for Developmental Education) Taskforce. (2007). Strategic planning evaluation of creating a new professional association. Retrieved June 24, 2009, from the CRLA website: http://www.crla.net/ WorkingGroupReporto91007.doc

Harbison, J. R., \& Pekar, P. (1998). Smart alliances: A practical guide to repeatable success. San Francisco: Jossey-Bass.

Nonaka, I., \& Nishiguchi, T. (Eds.). (2001). Knowledge emergence: Social, technical, and evolutionary dimensions of knowledge creation. New York: Oxford University Press.

Orlans, H. (1996, July/August). The most popular courses. Change Magazine, 28(4), 7.

Sullivan, L. H. (1896). The tall office building artistically considered. Retrieved June 24, 2009, from the Triton College website: http://academics.triton.edu/faculty/fheitzman/tallofficebuilding.html ()
"An invaluable manual" -Midwest Book Review

Teaching Unprepared Students

Strategies for

Promoting Success

and Retention

in Higher Education

KATHLEEN F. GABRIEL

Foreword by Sandra M. Flake

"[An] excellent resource to enhance retention." -Christine A. Stanley, Texas A\&M University

$20 \%$ DISCOUNT through 12/31/09. Use code JDEg9 when ordering toll free or on-line:

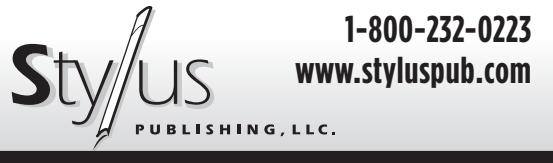

PROMOTING EXCELLENCE AMONG LEARNING CENTER PROFESSIONALS

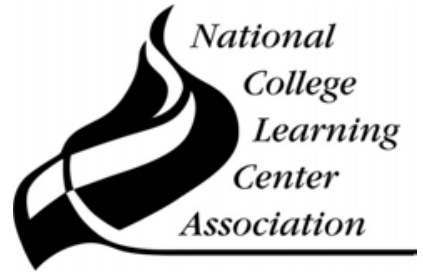

We are the association dedicated to learning center professionals.

Visit us at WWW.NCLCA.ORG

Some benefits of membership are:

- Journal Subscription (TLAR)

- Discounted registration to the Annual Conference (Fall) and NCLCA Institute (Summer)

- Regular issues of Newsletter

- Access to Members Only website resource materials

Annual Dues $\$ 50$

Student/Retiree $\$ 35$

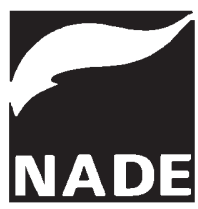

NADE News: Celebrating Collaborative Spirit ByKaren Patty-Graham, NADE President
The National Association for Developmental Education values the collaborative professional spirit that pervades developmentaleducation and NADE. We owe that spirit, in part, to many leaders in our freld. Recently we lost three of those leaders: Martha Maxwell, William "Bill" White, and Gene Kersteins. Martha Maxwell, a pioneer for over 50 years, left us valuable reading and study strategies, tutoring and learning center management techniques, the CLADEA Fellows program, and NADE's Mar tha Maxwell Developmental Education Student Scholarship. Bill White, Grambling State University faculty member and 2009-2010 CLADEA Fellow, left us numerous research initiatives and graduate students whom he mentered. Gene Kersteins, CLADEA Fellow and a founding member ef CRLA (College Reading \& Learning Association), left us his work in the assessment of student study behaviors. All influenced the growth and development of thousands of students and professionals. They will be missed but treasured for their legacies.

NADE actively pursues collaboration with its members and partners. For example, California NADE members and the Executive Board have worked over the last 18 months to-reate NADE's 31st active chapter, $\mathrm{Ga}$ HADE, to be installed at NADE 2010. President elect Marcella Davis and I recently participated with international educators in two roundtable discussions during the Forum for Access and Continuing Education (FACE) conference and met with FACE members interested in collaborating on math research with NADE members. The Certification Council partici pated in the Technology Institute for Developmental Educators (TIDE), as the first recipients of NADE'S TIDE Scholarship.

The NADE Board encourages you to read the position paper submitted to JDE by members of the CRLA/NADE Working Group. This collaborative group of authors presents a significant issue for NADE's consideration. Since the creation of the Blue Ribbon Commission, the Board has maintained the position that we will do what our members indicate they want based on what is best for the association and profession. The board respects our fellow associations and the educators they represent. We alse appreciate the thoughtful appreach taken by the authers in their work and article. The NADE Board is not in a position to-ither endorse or not en dorse the authors' proposal but would like to hear from members before advocating any move to form a new association. In the meantime, NADE centinues to provide quality professional development for educators while explering ways to cellaborate with the College Reading and Learning As sociation (CRLA), other Council for Learning Assistance and Developmental Education Associations (CLADEA) members, and additional as sociations with which NADE has reciprocal agreements. Please send your comments to NADE Secretary Betty Black, kfbjboo@tamuk.edu.

For additional information about NADE, consult the website at nadenet.

\section{NADE: Helping underprepared students prepare, prepared students advance, and advanced students excel!}

National Association for Developmental Education (NADE) • 500 N Estrella Parkway Ste B2 PMB 412 • Goodyear, AZ $85338 \bullet$ www.nade.net 